\title{
Does the Law of One Price Hold in a High-Inflation Environment? A Tale of Two Cities in Turkey
}

\author{
Sule Akkoyunlu, ETH Zurich \\ Boriss Siliverstovs, ETH Zurich
}

\begin{abstract}
This study addresses price convergence in two cities in Turkey (Istanbul and Ankara) using the annual data over the three quarters of the 20th century (1922-1998), characterized by prevailing high inflation rates for most of the period. In contrast to the rest of the literature addressing convergence in price levels with a typical result of extremely slow convergence rates at best, we argue that convergence is much easier detected in growth rates rather than levels of prices. We suggest using the bounds testing procedure of Pesaran et al. (2001) for this purpose. We find a clear-cut evidence on the existence of a common driving force behind inflation dynamics in Istanbul and Ankara - a finding that is intuitively appealing from the point of view of economic theory.
\end{abstract}

JEL code: C22, C32, C52, E31

Full paper in print. Please contact the author for details. 